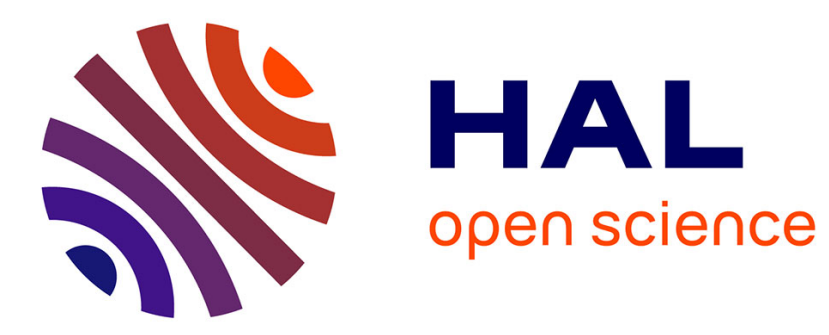

\title{
Effect of long-phase stratification treatments on seed germination in ash \\ Colin Doody, O’Reilly
}

\section{To cite this version:}

Colin Doody, O'Reilly. Effect of long-phase stratification treatments on seed germination in ash. Annals of Forest Science, 2011, 68 (1), pp.139-147. 10.1007/s13595-011-0015-0 . hal-00930720

\section{HAL Id: hal-00930720 https://hal.science/hal-00930720}

Submitted on 1 Jan 2011

HAL is a multi-disciplinary open access archive for the deposit and dissemination of scientific research documents, whether they are published or not. The documents may come from teaching and research institutions in France or abroad, or from public or private research centers.
L'archive ouverte pluridisciplinaire HAL, est destinée au dépôt et à la diffusion de documents scientifiques de niveau recherche, publiés ou non, émanant des établissements d'enseignement et de recherche français ou étrangers, des laboratoires publics ou privés. 


\title{
Effect of long-phase stratification treatments on seed germination in ash
}

\author{
Colin N. Doody • Conor O'Reilly
}

Received: 21 December 2009 / Accepted: 17 April 2010 /Published online: 15 February 2011

(C) INRA and Springer Science+Business Media B.V. 2011

\begin{abstract}
- Introduction Ash (Fraxinus excelsior L.) seeds require warm treatment followed by cold treatment to release dormancy and this is most effective if carried out in a medium. The objective of this study was to determine if long periods of warm treatment would enhance germination at 15 (8-h light) $/ 5^{\circ} \mathrm{C}$ (dark) and $15^{\circ} \mathrm{C}$ (same lighting conditions) in ash seeds of north-western European origin. - Materials and methods Ash seeds were fully imbibed (57\% moisture content (MC)) or adjusted to $45 \% \mathrm{MC}$ either in a medium or without a medium for 10-30 weeks of warm treatment, followed by 10,20 or 30 weeks of chilling.

- Results Germination increased at both germination temperature regimes as the duration of warm treatment increased up to 18 (with medium) or 20-30 (without medium) weeks, well after the embryo had completed development (14 weeks). The response to 20 or 30 weeks of chilling was better than that of 10 weeks of chilling, but the impact of chilling was smaller than that of warm treatment.

- Conclusion Seed MC did not significantly affect germination, but it reduced mould growth. A long warm treatment (followed by cold treatment) without a medium is the recommended treatment for ash seeds.
\end{abstract}

Keywords Warm treatment - Seed lot. Germination temperature $\cdot$ Chilling $\cdot$ Embryo growth

Handling Editor: Gilbert Aussenac

C. N. Doody $\cdot$ C. O'Reilly $(\bowtie)$

UCD School of Agriculture,

Food Science and Veterinary Medicine,

Agriculture and Food Science Centre,

University College Dublin,

Belfield,

Dublin 4, Ireland

e-mail: conor.oreilly@ucd.ie

\section{Introduction}

Common ash (Fraxinus excelsior L.) seeds ${ }^{1}$ become deeply dormant, and this must be broken before germination can occur. The dormancy mechanism is complex. At the time of dispersal in the autumn, the embryo of the ash seed is not fully developed (morphological dormancy) and only occupies about half the embryo cavity. Most embryo development occurs during the year following dispersal, predominantly in response to warm temperatures during the summer (Nowag 1998). Once the seed is mature, the seed coat and other structures, such as the pericarp, restrict growth of the embryo (mechanical dormancy) (Suszka et al. 1996). The seed coat also restricts gas exchange. In addition, a period of chilling is required to release dormancy in the mature embryo (physiological dormancy) (Villiers 1975). The requirement for a period of warmth followed by chilling means that germination does not occur until the second spring following dispersal. Germination may be delayed by slow decomposition of the seed coat or by the seed not receiving adequate warmth during the summer or sufficient chilling during the second winter (Suszka et al. 1996).

Seeds used in artificial regeneration can be allowed to break dormancy naturally outside or alternatively artificially in an incubator or growth chamber (Obroucheva and Antipova 2000). Clearly, it is more difficult to optimise temperatures under ambient conditions outside, so it may be preferable to carry out the pretreatment under controlled conditions. The ISTA (2006) standard treatment for the

\footnotetext{
${ }^{1}$ Ash seeds are contained in fruits called samaras. Samaras are winglike structures, about $40 \mathrm{~mm}$ long and 6-8 $\mathrm{mm}$ wide. Each samara contains one seed. For convenience in this paper, the term seed will be used to refer to the samara.
} 
warm phase for common ash is 8.6 weeks (60 days) at $20^{\circ} \mathrm{C}$. However, the optimal duration of the warm phase has been found to range from 8 to 18 weeks (Tylkowski 1990; Nowag 1998) and there is little information for periods longer than 20 weeks (Derkx 2000). While temperatures of $10-20^{\circ} \mathrm{C}$ during the warm phase result in acceptable germination, Muller (1993) and Derkx (2000) found that $15^{\circ} \mathrm{C}$ was the optimal temperature to break dormancy during the warm phase in seeds of continental European provenances of ash. Temperatures from $10^{\circ} \mathrm{C}$ to $15^{\circ} \mathrm{C}$ are sub-optimal and those lower than $10^{\circ} \mathrm{C}$ are not sufficient to initiate embryo development (Suszka et al. 1996). Temperatures higher than $20^{\circ} \mathrm{C}$ may induce secondary dormancy in non-dormant seeds (Suszka 1978; Piotto 1994). ISTA (2006) recommend following the warm phase with 30 weeks of chilling at $3-5^{\circ} \mathrm{C}$. However, temperatures of $1-5^{\circ} \mathrm{C}$ are equally effective for the cold phase and the optimal duration is generally considered to be $12-16$ weeks (Tylkowski 1990; Nowag 1998).

Ash seeds are usually placed in a medium (sand, soil, peat or other materials such as vermiculite or perlite) during the pretreatment period. Under operational conditions, pretreatment (often referred to as "stratification") usually involves placing the seeds in pits outside in a medium to expose them to natural conditions during the summer and winter prior to sowing. The medium helps to minimise desiccation and fungal damage (Gordon 1992). However, Muller (1993) and Jinks et al. (1995a, b) have shown that dormancy can be broken successfully without a medium, but the rate of embryo growth was slowed during the warm phase compared with seeds pretreated in a medium. There is little other information on the effect of a medium on seed dormancy in ash, particularly its potential effect on premature germination.

Given the wide natural distribution range of common ash, from southern Scandinavia to the north of Iran and from Ireland to northern Turkey (Suszka et al. 1996), it is likely that the optimal pretreatment to remove dormancy may vary greatly. Summer temperatures are cooler and winter temperatures are milder in Ireland than in most parts of the rest of Europe. The seed dormancy mechanism may reflect adaptations to these climatic conditions, so the dormancy response may differ from that reported in the literature for more southerly and continental sources of common ash.

The use of a lower seed moisture content (MC) than the fully imbibed (FI) state may offer some advantages. The intention is to provide sufficient moisture to allow embryo development to take place, but it might be possible to pretreat without a medium if mould growth can be arrested also. The water requirements to break dormancy during pretreatment or stratification is usually lower than that required for germination (Baskin and Baskin 1998). The use of a lower MC also allows a longer and generally more beneficial chilling period to be used to break dormancy in all seeds, while also reducing the risk of premature germination in any sub-population of seeds that have their requirements fulfilled early (Derkx 2000).

The ISTA (ISTA 2006) standard for germinating ash seed under test conditions is $8 \mathrm{~h}$ at $30^{\circ} \mathrm{C}$ (light) and $16 \mathrm{~h}$ at $20^{\circ} \mathrm{C}$ (dark). However, this regime has been found to be sub-optimal for some ash species, including common ash (Muller 1993; Piotto 1994). Suszka (1978) found that alternating light/dark temperatures of $15 / 5^{\circ} \mathrm{C}$ was optimal for germination. The fluctuating temperatures appear to mimic the natural alternations between night and day, such as might be expected during the spring. The $15^{\circ} \mathrm{C}$ treatment appears to allow germination to take place without the risk of inducing secondary dormancy and the $5^{\circ} \mathrm{C}$ treatment may help to break dormancy in any sub-populations of seeds that remained dormant following pretreatment. It is desirable that seed pretreatments reduce the sensitivity of seeds to temperatures (especially high ones), since post-sowing conditions may vary greatly depending on sowing date.

The main aim of this study was to determine the effects of long warm phase durations (up to 30 weeks) on the germination response at a constant temperature of $15^{\circ} \mathrm{C}$ or alternating temperatures of $15 / 5^{\circ} \mathrm{C}$ in two Irish seed lots of common ash. A secondary aim was to examine the effects of chilling duration (10-30 weeks), seed MC (57\% MC, fully imbibed; or $45 \% \mathrm{MC}$ ) with or without the presence of a medium. The effects of these treatments on embryo development, premature germination (before the tests began), percentage germination and germination speed were examined. There is little information to this end, especially for the north-western European provenances of the species.

\section{Materials and methods}

\subsection{Seed material}

Two seed lots of ash provided by Coillte Seed Centre (Ballintemple, Carlow, Ireland) were used in this experiment, which took place from September 2005 to July 2007. The physical and viability characteristics of the seeds of each lot are given in Table 1. The two seed lots had MC of $14.8 \%$ and $12.9 \%$ at time of arrival in the laboratory and the viability, from official tetrazolium tests conducted elsewhere following ISTA guidelines, was $87 \%$ and $92 \%$.

\subsection{Seed moisture content treatments}

Seeds of each lot were soaked in tap water ( 3 water/ 1 seed vol./vol.) for $48 \mathrm{~h}$ at $3^{\circ} \mathrm{C}$. The results of preliminary trials revealed that this period was long enough to fully imbibe 
Table 1 Physical and viability characteristics of the seeds used in the experiment

\begin{tabular}{llccc}
\hline Seedlot & Seed origin and seed zone & Moisture content (\%) & Year of seed maturation & Viable seed (kg $\left.{ }^{-1}\right)$ \\
\hline B74 & Cork, Ireland 417 & 14.8 & 2001 & 12,200 \\
D113 & Cork, Ireland 417 & 12.9 & 2003 & 12,814 \\
\hline
\end{tabular}

All treatments/observations were carried out according to ISTA rules by the Department of Agriculture, Backweston Laboratory Complex, Celbridge, Co. Kildare, Ireland

ash seeds. The water was changed after approximately $24 \mathrm{~h}$. After soaking, the seeds were surface dried using paper towels. The MC of the seeds after soaking was determined based on four replicates of five seeds each, sampled at random from each lot. Each replicate of seeds was weighed and then dried at $105^{\circ} \mathrm{C}$ for $24 \mathrm{~h}$ and then reweighed. The MC of the fully imbibed seeds of both lots was approximately $57 \%$.

In addition to the FI ones, seeds of each lot were dried back from the FI state to a target MC (TMC) of $45 \%$, on a weight loss basis. The seeds were allowed to dry on trays at room temperature (approximately, $18-22^{\circ} \mathrm{C}$ ) for about $6 \mathrm{~h}$ and were mixed regularly to maximise the uniformity of drying. The seeds were weighed before drying and thereafter at regular intervals until they had reached $45 \%$ $\mathrm{MC}$, as calculated by the formula $F W_{2}=\frac{F W_{1(100-M C 1)}}{100-M C_{2}}$ (where $\mathrm{FW}_{2}$ is the dried weight, $\mathrm{FW}_{1}$ is the known fresh weight, $\mathrm{MC}_{1}$ is the known $\mathrm{MC}$ and $\mathrm{MC}_{2}$ is the desired $\mathrm{MC}$ after drying) (Suszka et al. 1996). After drying, seed MC was checked using the oven method, following the same sampling procedure described above.

\subsection{Dormancy breakage}

After adjusting seeds to FI and TMC levels, one half of the seeds (weight basis) of each treatment were placed in rectangular plastic boxes $(17 \times 10.5 \times 6 \mathrm{~cm}$; Hofstatter \& Ebbesen A/S, Espergaerde, Denmark), covered and then subjected to combinations of treatments to break dormancy. The other half of the seeds of each treatment were mixed in a bucket with a medium consisting of equal volumes of seed, peat, fine perlite and sand (1:1:1:1; vol./vol./vol./vol.) and then placed in boxes (the same box type as above). The boxes were then weighed, after which they were placed in an incubator at $15^{\circ} \mathrm{C}$ in darkness for $10,14,18,22,26$ or 30 weeks. The boxes were weighed at weekly intervals and a sample of seeds from each box was removed at 2-week intervals to determine seed MC (using the oven method as described above). Water was added (approximately every 46 weeks) when it had declined by more than one percentage point. The amount of water required varied and was determined by the formula given above. The seeds were mixed at weekly intervals to minimise moisture losses and to reduce the accumulation of water at the bottom of the boxes.
At the end of each warm phase, the seeds (either with or without a medium) were removed from the boxes and placed in plastic bags $(30 \times 20 \mathrm{~cm}, 500$ gauge; The Packaging Centre, Dublin 22, Ireland). The seeds were then chilled at $3 \pm 1^{\circ} \mathrm{C}$ for 10,20 or 30 weeks. The same steps were taken to monitor and maintain seed MC during chilling as during the warm phase, but seed MC changed little during chilling.

The results of previous preliminary trials revealed that there was little change in embryo length until after week 10 of the warm phase. Therefore, the length of the embryo and the embryo cavity were measured at 2-week intervals beginning at week 10 of the warm phase. On each occasion, 15 seeds were sampled per treatment; each seed was bisected and measured under a dissecting microscope. The embryos of seeds that received 10 weeks of warm treatment were also measured at the end of each chilling phase since embryo elongation had not ceased prior to chilling.

\subsection{Germination tests}

Each treatment combination was represented by four replications of 25 seeds each. The seeds were placed on cotton wool moistened with distilled water in rectangular plastic boxes $(12 \times 8 \times 4.5 \mathrm{~cm}$; Hofstatter \& Ebbesen A/S, Espergaerde, Denmark). The boxes were placed in incubators at $15^{\circ} \mathrm{C}$ or $15 / 5^{\circ} \mathrm{C}$ (light/dark) with $8 \mathrm{~h}$ of lighting per day. The number of seeds that germinated was recorded twice weekly for 45 days. A seed was considered to have germinated when the radicle was $5 \mathrm{~mm}$ long. Mean germination time (MGT) was calculated as the mean number of days for seeds to germinate during the 45-day test period (after Jones and Gosling 1994).

The number of seeds that germinated prematurely during chilling was determined separately at the end of each chilling treatment. A sample of 100 seeds was examined and any visible (approximately, $>2 \mathrm{~mm}$ ) radicle emergence was recorded.

\subsection{Data analyses and presentation}

The data were analysed according to a full factorial ANOVA, but for simplicity the three- and four-way interaction effects are not presented. The effects of seed 
lot (two levels), seed MC (two levels), warm phase duration (six levels) chilling phase duration (three levels), germination temperature (two levels) and their interactions on percentage seed germination and MGT were examined using the GLM procedure in SAS (SAS 1999). Percentage data were transformed to arc-sine square-root values before analyses. Premature germination was analysed according to the same model, but the analysis was restricted to the longer $(>22$ weeks) warm and cold treatments $(>10$ weeks) for seeds treated in a medium. Few seeds germinated prematurely in response to the other treatments. All data were also analysed separately by temperature and medium.

\section{Results}

\subsection{Embryo development and pre-germination}

Little embryo development (as percentage of cavity) occurred from weeks 10 to 12 (Fig. 1). Most development was completed between weeks 12 and 14 . The embryos of seeds held with a medium had completed this process earlier than those held without a medium. The embryos of seeds given 10 weeks of warm treatment, which had not completed their growth during the warm phase, had ceased growth by the end of the 10 -week chilling phase. There was no significant difference between seed lots in the rate of embryo development.

Warm treatment duration and chilling duration had the largest effects on premature germination (Table 2). The effects of treatments on total germination, including (inset) and excluding premature germination (main graph), are shown in Fig. 2. Seeds in a medium that received 26 or 30 weeks of warm treatment followed by 20 or 30 weeks of

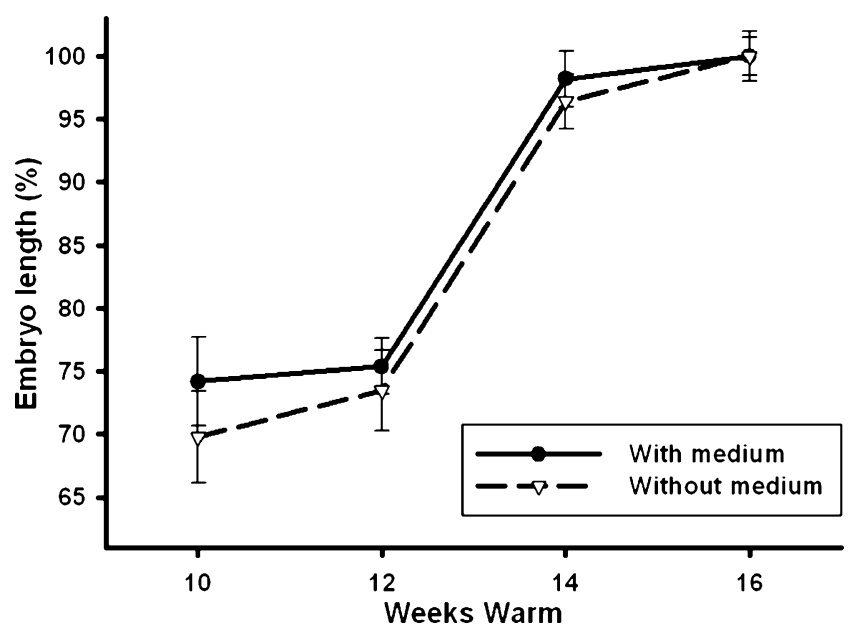

Fig. 1 Mean embryo length as percentage of embryo cavity length in ash seeds. The vertical lines on symbols are standard errors. Each mean is based on four replications containing 100 seeds each
Table 2 ANOVA of the effects of seed lot, moisture content, medium, warm phase and chilling phase on pre-germination in ash seeds given 26 or 30 weeks of warm treatment followed by 20 or 30 weeks of chilling treatment

\begin{tabular}{llrrr}
\hline \multirow{2}{*}{ Source of variation } & \multicolumn{4}{l}{ Germination } \\
\cline { 2 - 5 } & $d f$ & MS & $F$ & $P$ \\
\hline Seed lot (S) & 1 & 479 & $2,041.7$ & $<0.0001^{*}$ \\
Medium (M) & 1 & 130,245 & 555.1 & $<0.0001^{*}$ \\
Moisture content (MC) & 1 & 1 & 5.4 & $0.0266^{*}$ \\
Warm phase (W) & 1 & 777 & $3,315.3$ & $<0.0001^{*}$ \\
Chilling phase (C) & 1 & 468 & $1,995.3$ & $<0.0001^{*}$ \\
$\mathrm{~S} \times \mathrm{M}$ & 1 & 425 & $1,815.0$ & $<0.0001^{*}$ \\
$\mathrm{~S} \times \mathrm{MC}$ & 1 & 84 & 355.3 & $<0.0001^{*}$ \\
$\mathrm{~S} \times \mathrm{W}$ & 1 & 58 & 248.1 & $<0.0001^{*}$ \\
$\mathrm{~S} \times \mathrm{C}$ & 1 & 5 & 19.3 & $<0.0001^{*}$ \\
$\mathrm{M} \times \mathrm{MC}$ & 1 & 58 & 248.1 & $<0.0001^{*}$ \\
$\mathrm{M} \times \mathrm{W}$ & 1 & 657 & $2,801.7$ & $<0.0001^{*}$ \\
$\mathrm{M} \times \mathrm{C}$ & 1 & 523 & $2,232.6$ & $<0.0001^{*}$ \\
$\mathrm{MC} \times \mathrm{W}$ & 1 & 32 & 135.0 & $<0.0001^{*}$ \\
$\mathrm{MC} \times \mathrm{C}$ & 1 & 6 & 24.1 & $<0.0001^{*}$ \\
$\mathrm{~W} \times \mathrm{C}$ & 1 & 329 & $1,401.1$ & $<0.0001^{*}$ \\
\hline & & & &
\end{tabular}

${ }^{*} P<0.05$, significant values

chilling, regardless of seed $\mathrm{MC}$, resulted in relatively high rates of premature germination. For seeds germinated at 15/ $5^{\circ} \mathrm{C}$ given 26 weeks of warm followed by 30 weeks of chilling treatment for example, $13 \%$ of the seeds germinated prematurely $(81 \%$ including pre-germination compared with $68 \%$ for germination excluding prematurely germinated seeds). Some seeds that were pretreated without medium, or in a medium for 26 or 30 weeks and received only 10 weeks of chilling, germinated prematurely but the incidence was lower than $5 \%$ in all cases.

3.2 Germination temperature, medium, seedlot and MC effects on germination

As expected, germination temperature had a massive effect on both percentage germination and MGT. For this reason, the data are analysed and presented separately by germination temperature. In addition, the presented data are separated by medium, mainly to improve the clarity of presentation.

Seeds of lot D113 germinated better and more quickly in response to shorter durations of warm treatment than those of B74, as reflected in the significant interaction between these treatments (Tables 3 and 4). Similar trends were apparent for some other interactions with seed lot. Seeds that were treated at the lower MC generally had slightly higher germination, but this was recorded mainly for those 
Fig. 2 Germination response of ash seeds at alternating or constant temperatures. The seeds received warm treatment followed by chilling, with or without a medium before testing. Inset graphs show total germination including pregermination. The vertical lines on symbols are standard errors. Each mean is based on 16 replications containing 25 seeds each

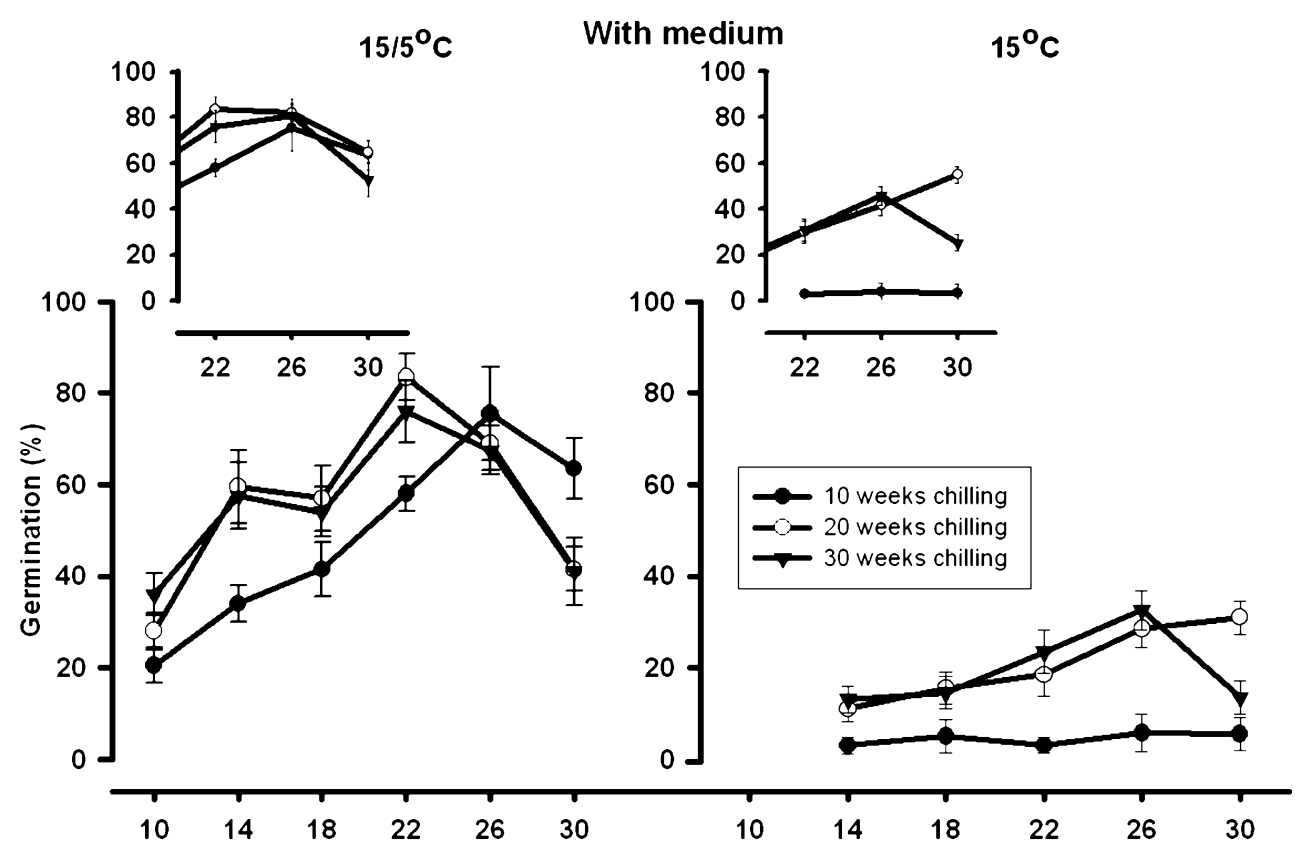

Without medium

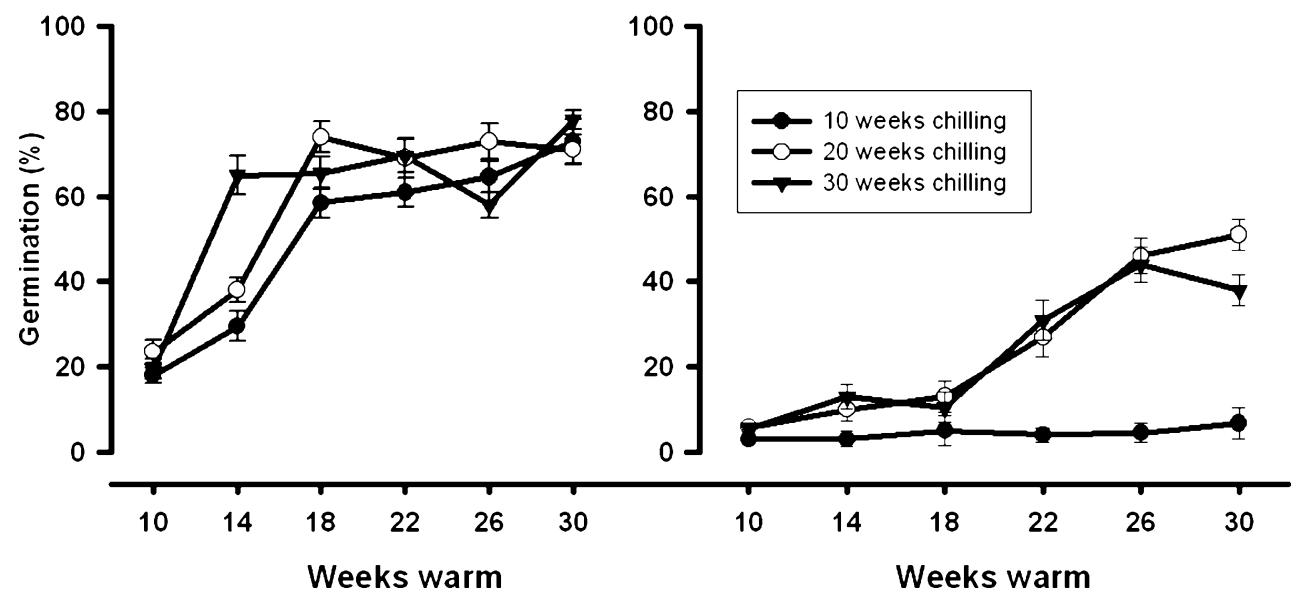

given long periods of warm treatment followed by 20 or 30 weeks of chilling. A similar trend was noted for MGT. However, both seedlot and MC effects were small and mostly consistent, so they are not described further. The mean values for both seedlots and MC are presented throughout the paper for this reason.

\subsubsection{Germination}

Germination was higher under the alternating temperature of $15 / 5^{\circ} \mathrm{C}$ than at the constant $15^{\circ} \mathrm{C}$, regardless of treatment (Fig. 2). In general, warm duration, chilling and their interactions had the largest effects on germination (Table 3). Germination increased as the length of the warm phase and chilling period increased, with the increase being most dramatic at the constant $15^{\circ} \mathrm{C}$. Seeds reached maximum germination following 22 weeks of warm treatment with a medium $(81 \%)$ or 18 weeks without a medium $(74 \%)$ when germinated at $15 / 5^{\circ} \mathrm{C}$. Germination was lower at a constant $15^{\circ} \mathrm{C}$, with the maximum being reached following 30 weeks of warm treatment both with $(33 \%)$ and without $(51 \%)$ a medium following 30 weeks of chilling.

Chilling duration also significantly affected germination, but to a lesser extent than warm duration (Table 3). Germination was significantly higher for seeds given 20 or 30 weeks of chilling than for those that received 10 weeks of chilling at both germination temperatures. The difference in germination between those given 20 compared with 30 weeks of chilling was small. However, few or no seeds germinated at a constant $15^{\circ} \mathrm{C}$ following 10 weeks of chilling, regardless of the length of warm treatment received (Fig. 2). Germination at $15 / 5^{\circ} \mathrm{C}$ was 
Table 3 ANOVA of the effects of seed lot, medium, moisture content, warm phase and chilling phase on germination in ash

\begin{tabular}{|c|c|c|c|c|c|c|c|}
\hline \multirow[t]{2}{*}{ Source of variation } & \multirow[t]{2}{*}{$d f$} & \multicolumn{3}{|l|}{$15 / 5^{\circ} \mathrm{C}$} & \multicolumn{3}{|l|}{$15^{\circ} \mathrm{C}$} \\
\hline & & MS & $F$ & $P$ & MS & $F$ & $P$ \\
\hline Seed lot (S) & 1 & 51 & 0.6 & 0.4387 & 25 & 0.7 & 0.4066 \\
\hline Medium (M) & 1 & 295 & 3.3 & 0.0694 & 544 & 15.0 & $<0.0001^{*}$ \\
\hline Moisture content (MC) & 1 & 1,835 & 21.5 & $<0.0001^{*}$ & 2,240 & 61.9 & $<0.0001 *$ \\
\hline Warm phase (W) & 5 & 27,344 & 319.9 & $<0.0001 *$ & 9,042 & 249.6 & $<0.0001^{*}$ \\
\hline Chilling phase (C) & 2 & 3,900 & 45.6 & $<0.0001 *$ & 23,642 & 652.7 & $<0.0001^{*}$ \\
\hline $\mathrm{S} \times \mathrm{M}$ & 1 & 1,640 & 19.2 & $<0.0001 *$ & 400 & 11.0 & $0.0010^{*}$ \\
\hline $\mathrm{S} \times \mathrm{MC}$ & 1 & 295 & 3.5 & 0.0640 & 2,500 & 69.0 & $<0.0001^{*}$ \\
\hline $\mathrm{S} \times \mathrm{W}$ & 5 & 1,009 & 11.8 & $<0.0001 *$ & 557 & 15.4 & $<0.0001^{*}$ \\
\hline $\mathrm{S} \times \mathrm{C}$ & 2 & 222 & 2.6 & 0.0758 & 114 & 3.16 & $0.0436^{*}$ \\
\hline $\mathrm{M} \times \mathrm{MC}$ & 1 & 820 & 10.2 & $0.0015^{*}$ & 625 & 17.3 & $<0.0001^{*}$ \\
\hline $\mathrm{M} \times \mathrm{W}$ & 5 & 3,505 & 41.0 & $<0.0001 *$ & 441 & 12.2 & $<0.0001^{*}$ \\
\hline $\mathrm{M} \times \mathrm{C}$ & 2 & 2 & 0.1 & 0.9785 & 205 & 5.7 & $0.0038^{*}$ \\
\hline $\mathrm{MC} \times \mathrm{W}$ & 5 & 406 & 4.8 & $<0.0001 *$ & 426 & 11.8 & $<0.0001 *$ \\
\hline $\mathrm{MC} \times \mathrm{C}$ & 2 & 262 & 3.1 & $0.0479 *$ & 162 & 4.5 & $0.0119^{*}$ \\
\hline $\mathrm{W} \times \mathrm{C}$ & 10 & 1,344 & 15.7 & $<0.0001^{*}$ & 319 & 88.0 & $<0.0001 *$ \\
\hline
\end{tabular}

${ }^{*} P<0.05$, significant values

\subsubsection{Germination speed}

chilling than those that received 20 or 30 weeks of chilling.

Maximum germination ( $81 \%$ ) was achieved at $15 / 5^{\circ} \mathrm{C}$ for seeds given 22 weeks warmth in a medium, but values declined thereafter as the period of warmth increased. The decline in germination after 22 weeks warmth for seeds pretreated in a medium was mainly due to pre-germination. However, germination was consistently high (60-74\%) over long periods of warm treatment (18-30 weeks followed by 20 or 30 weeks of chilling) for those treated without a medium (Fig. 2). Germination at $15^{\circ} \mathrm{C}$ was higher for seeds pretreated without a medium than those pretreated with a medium.
MGT values for treatment combinations that resulted in $<30 \%$ germination (Fig. 3) are not considered important since they reflected a relatively small sub-population of seeds. This category included: (1) most treatment combinations with a medium for seeds germinated at $15^{\circ} \mathrm{C}$ (constant) following $<22$ weeks of warm treatment; (2) seeds given 20 or 30 weeks of chilling without a medium that had been germinated at $15^{\circ} \mathrm{C}$ (constant); and (3) a few 10 -week warm phase treatment combinations for those germinated at $15 / 5^{\circ} \mathrm{C}$.
Table 4 ANOVA of the effects of seed lot, medium, moisture content, warm phase and chilling phase on mean germination (MGT) time in ash

\begin{tabular}{|c|c|c|c|c|c|c|c|}
\hline \multirow[t]{2}{*}{ Source of variation } & \multirow[t]{2}{*}{$d f$} & \multicolumn{3}{|l|}{$15 / 5^{\circ} \mathrm{C}$} & \multicolumn{3}{|l|}{$15^{\circ} \mathrm{C}$} \\
\hline & & MS & $F$ & $P$ & MS & $F$ & $P$ \\
\hline Seed lot (S) & 1 & 30 & 1.6 & 0.2053 & 130 & 6.4 & $0.0122^{*}$ \\
\hline Medium (M) & 1 & 190 & 10.1 & $0.0016^{*}$ & 196 & 4.7 & $0.0312^{*}$ \\
\hline Moisture content (MC) & 1 & 208 & 11.0 & $0.0010^{*}$ & 13 & 0.6 & $0.4328^{*}$ \\
\hline Warm phase (W) & 5 & 119 & 59.4 & $<0.0001 *$ & 1,683 & 82.7 & $<0.0001^{*}$ \\
\hline Chilling phase (C) & 2 & 2,449 & 129.9 & $<0.0001 *$ & 1,490 & 73.3 & $<0.0001^{*}$ \\
\hline $\mathrm{S} \times \mathrm{M}$ & 1 & 1.8 & 0.1 & 0.7554 & 103 & 5.1 & $0.0255^{*}$ \\
\hline $\mathrm{S} \times \mathrm{MC}$ & 1 & 53 & 2.8 & 0.0950 & 145 & 7.1 & $0.0081^{*}$ \\
\hline $\mathrm{S} \times \mathrm{W}$ & 5 & 103 & 5.5 & $<0.0001^{*}$ & 243 & 11.9 & $<0.0001^{*}$ \\
\hline $\mathrm{S} \times \mathrm{C}$ & 2 & 399 & 21.2 & $<0.0001 *$ & 58 & 2.8 & $0.0604^{*}$ \\
\hline $\mathrm{M} \times \mathrm{MC}$ & 1 & 58 & 3.1 & 0.0807 & 2 & 0.1 & 0.7379 \\
\hline $\mathrm{M} \times \mathrm{W}$ & 5 & 188 & 10.0 & $<0.0001^{*}$ & 103 & 5.1 & $0.0006^{*}$ \\
\hline $\mathrm{M} \times \mathrm{C}$ & 2 & 128 & 6.8 & $0.0013 *$ & 58 & 2.8 & $0.0612 *$ \\
\hline $\mathrm{MC} \times \mathrm{W}$ & 5 & 173 & 9.2 & $<0.0001^{*}$ & 35 & 1.7 & 0.1439 \\
\hline $\mathrm{MC} \times \mathrm{C}$ & 2 & 3 & 0.2 & 0.8488 & 0.3 & 0.1 & 0.9845 \\
\hline $\mathrm{W} \times \mathrm{C}$ & 10 & 281 & 14.9 & $0.0001^{*}$ & 619 & 30.4 & $<0.0001 *$ \\
\hline
\end{tabular}


Fig. 3 Mean germination time $(M G T)$ of ash seeds at alternating or constant temperatures. The seeds received warm treatment followed by chilling, with or without a medium, before testing. The vertical lines on symbols are standard errors. Each mean is based on 16 replications containing 25 seeds each
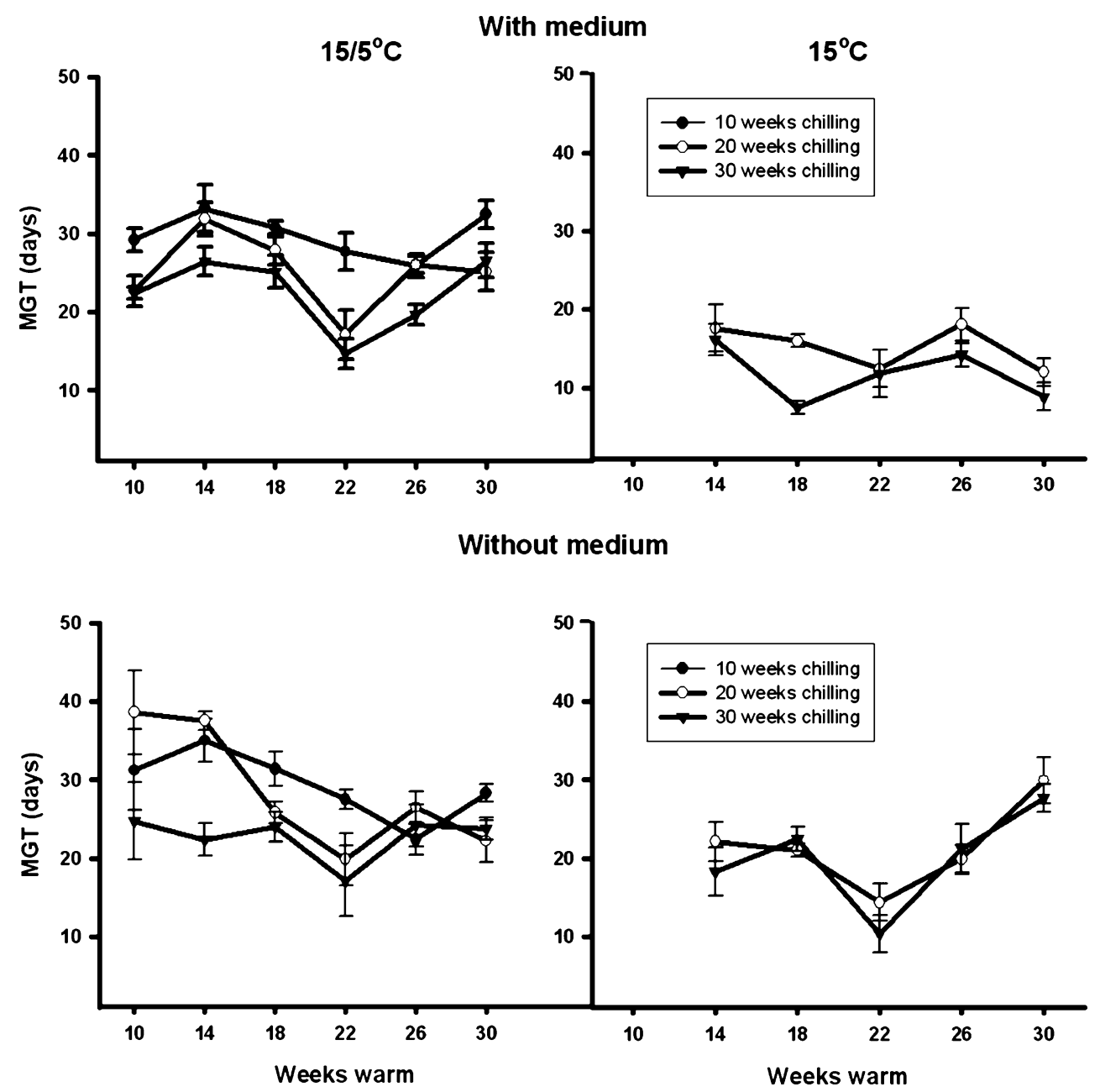

Warm and chilling durations and their interactions significantly affected germination speed at both test temperatures (Table 4). At $15 / 5^{\circ} \mathrm{C}$, MGT was generally lower (i.e. germination speed was higher) as warm phase duration was increased up to 22 weeks (Fig. 3). For seeds germinated at $15^{\circ} \mathrm{C}$, warm duration had little effect on seeds given 10 weeks chilling. Following 26 or 30 weeks of warm treatment, germination speed was lower in seeds pretreated without medium than with a medium. In seeds pretreated without a medium, germination speed increased following long warm treatments up to 26 weeks. Seeds germinated more quickly, on average, following 30 than 20 weeks of chilling, but the difference was generally small (and not significant for most warm durations).

\section{Discussion}

The main finding of this study was that seed maturation and other processes that are activated during the warm phase (of the warm plus cold stratification), after the embryo has fully developed, greatly influence seed germination and sensitivity to germination temperature in north-western European origin ash. Furthermore, additional chilling does not fully compensate for inadequate warm treatment. The importance of seed maturation for germination has been shown for the many tree species. Post-harvest "after ripening" (during which the seeds are also dried back) has been found to reduce the duration of chilling required to break dormancy in seeds of Sorbus mougeotii Soyer Will. and Godron (Jensen 2003) and Prunus avium L. (FinchSavage et al. 2002). Although the exact mechanism is not known, presumably a similar process to after ripening occurred during the warm phase in the moist ash seeds in this study.

Although it is generally accepted that embryo length is the main indicator of dormancy progress during the warm phase in ash (Derkx 2000), the results of this study suggest that maturation after this stage is also important (max germination potential was achieved 4-8 weeks after the embryo had fully occupied the cavity). The long warm treatment may have stimulated embryo dormancy release, but it may also have helped to release mechanical dormancy (by softening and hastening decay of the seed coat and other 
structures) (see Muller 1993; Wagner 1996). However, the exact mechanism was not determined in this study.

Long periods of warm pretreatment greatly increased germination at both test temperatures. To the authors' knowledge, a reduction in temperature sensitivity in response to pretreatment has not been previously reported for common ash, although it is well known that pretreatments generally widen the range of temperatures within which germination can occur (Baskin and Baskin 1998). Nevertheless, seeds germinated better at $15 / 5^{\circ} \mathrm{C}$ than at a constant $15^{\circ} \mathrm{C}$. The lower temperature $\left(5^{\circ} \mathrm{C}\right)$ of the alternating regime may slow metabolic rates sufficiently to allow more oxygen to become available to pathways promoting germination (Villiers 1975) and it may also provide additional chilling. Chilling removes metabolic blocks, favours promoters (Leadam 1997) and activates enzyme systems which convert stored food reserves into more soluble forms (Bewley and Black 1994). In seeds of common ash, food reserves are initially stored as oil but are converted to carbohydrates and proteins (Villiers and Wareing 1965). Therefore, it is not surprising that ash seeds responded better to alternating temperatures than constant ones (that resemble those in early spring). The periods of warm treatment which were considered optimal (18-30 weeks) to maximise germination in the northwestern European origin ash seeds used in this study were longer than the 8.6 weeks ( 60 days) recommended by ISTA (2006) and those (max 20 weeks) previously recommended for continental European provenances of ash (Suszka 1978; Muller 1993; Piotto 1994; ISTA 2006; Derkx 2000).

Although long warm treatment durations increased germination, chilling treatments longer than 20 weeks did not further enhance the response. Nevertheless, seeds that received the optimal warm pretreatment maintained a high germination potential for up to 30 weeks of chilling, compared with 16-20 weeks in a previous report (Derkx 2000). In this study, 10 weeks of chilling appeared to be sub-optimal to break physiological dormancy in the seeds given 10 or 14 weeks of warm treatment and was less effective than 20 or 30 weeks of chilling in the seeds given longer than 14 weeks of warm treatment.

Another important finding of this study, in agreement with a previous report by Muller (1993), was that ash seeds can be pretreated effectively without a medium. In contrast, Derkx (2000) reported poor embryo development for seeds treated without a medium compared with those treated in a medium of sand or sand with sphagnum peat (max 20 weeks). In this study, there was a long plateau period (18-30 weeks) over which germination was high for seeds pretreated without a medium, whereas seed germination began to decline after reaching a peak (ca. 22 weeks) for those pretreated in a medium. The pericarp and/or other structures surrounding the embryo degrade quickly in a medium, especially in peat, so embryo development and dormancy release might be expected to progress more rapidly (Suszka 1978; Muller 1993; Finch-Savage and Clay 2007), perhaps resulting in much premature germination during the chilling phase.

Under operational conditions where the seeds are usually pretreated in a medium outside in a pit, it would be difficult to recommend a warm treatment prescription since ambient conditions vary greatly. Therefore, there is a risk that seeds could exceed the heat requirement (equivalent to 22 weeks at $15^{\circ} \mathrm{C}$ ), possibly leading to deterioration, or alternatively receive insufficient warmth to elicit a good response. Pretreatment without a medium is preferable since the optimum warm period duration is long (18-30 weeks), giving greater flexibility. Seeds given long warm pretreatment without a medium might be expected to germinate better in the nursery, particularly if sown late in season when temperatures are higher (little or no night chilling). High temperatures at this stage potentially might expose the seeds to the risk of developing secondary dormancy. In addition, sowing delays are likely to extend the chilling period, leading to a greater reduction in germination potential during chilling for seeds pretreated with a medium. Although the results appear promising, nursery trials are needed to confirm the benefits of using a long warm treatment without a medium.

MC had little effect on germination and premature germination was not completely prevented at the lower MC (45\%). However, the use of a lower MC may be more advantageous, especially if a medium is not used, mainly because fungal infection rates (which may be more problematic in a large stratification pit) are reduced (Gordon 1992). The lowest MC used in this study (45\%) was not sufficient to prevent premature germination. However, Derkx (2000) reported that premature germination was prevented at a seed $\mathrm{MC}$ of $42 \%$ during chilling. Prematurely germinated seeds are prone to deterioration during handling and sowing operations (Suszka 1978). There are also concerns that such losses may adversely affect genetic diversity, since seeds with a lower stratification requirement are eliminated.

\section{Conclusions}

The germination of ash seeds in this study increased at both alternating $15 / 5^{\circ} \mathrm{C}$ and constant $15^{\circ} \mathrm{C}$ with increasing warm treatment duration up to 22 (alternating) or 22-30 (constant) weeks. This response probably was mediated largely through the effect on the seed maturation process (after embryo growth had been completed), but mechanical dormancy release may also have been affected. Although germination reached a slightly higher maximum for seeds 
treated with than without a medium, high germination potential can be achieved over a longer period of warmth without a medium. Seed MC did not greatly affect germination, but it may be preferable to pretreat seeds at a lower seed $\mathrm{MC}$ than the FI state because it reduces mould growth.

\section{References}

Baskin JM, Baskin CC (1998) Seeds: ecology, biogeography and evolution of dormancy and germination. Academic, London, p 666

Bewley JD, Black M (1994) Seeds: physiology of development and germination. Plenum, New York, p 445

Derkx MPM (2000) Pre-treatment at controlled seed moisture content as an effective means to break dormancy in tree seeds. In: Viemont JD, Grabbe J (eds) Dormancy in plants: from whole plant behaviour to cellular control. CABI, New York, p 385

Finch-Savage WE; Clay HA (2007) The influence of embryo restraint during dormancy loss and germination of Fraxinus excelsior seeds. In: Basic and applied aspects of seed biology. Proceedings of the Fifth International Workshop on Seeds, Reading, UK, 10 15 December 1995. Kluwer, Dordrecht

Finch-Savage WE, Clay HA, Dent KC (2002) Seed maturity affects the uniformity of cherry (Prunus avium L) response to dormancy-breaking treatments. Seed Sci Technol 30(3):483-497

Gordon AG (1992) Seed manual for forest trees. HMSO, London, p 132

ISTA (2006) International rules for seed testing. Seed Sci Technol (supplement) 21:1

Jinks R, Jones J, Gosling P (1995a) Improving the pre-treatment and germination of broadleaved seed. For Br Timber 24(12):24-26

Jensen M (2003) Effect of seed maturity and pretreatment on dormancy and germination of Sorbus mougeotii seeds. Scand J For Res 18(6):479-486

Jinks $\mathrm{R}$ et al (1995b) Improving the pre-treatment and germination of broadleaved seed. For Br Timber 24(12):24-26
Jones SK, Gosling PG (1994) "Target moisture content" prechill overcomes the dormancy of temperate conifer seeds. New For 8:309-321

Leadam CL (1997) Dormancy — unlocking seed secrets. In: Landis T D, Thompson, JR, tech cords (eds). National Proceedings, Forest and Conservation Nursery Associations. Gen. Tech. Rep. PNW-G TR419. U.S. Department of Agriculture, Forest Service, Pacific Northwest Research Station, Portland, OR. pp 43-52

Muller C (1993) Combination of dormancy-breaking and storage for tree seeds; new strategies for hardwood species. In: Dormancy and barriers to germination. Proceedings of an international symposium of IUFRO Group P2.04, Victoria, BC

Nowag A (1998) Management of seed dormancy in Fagus sylvatica, Fraxinus excelsior and Prunus avium. Comb Proc Int Plant Propag Soc 48:192-199

Obroucheva NV, Antipova OV (2000) The distinct controlling of dormancy release and germination commencement in seeds. In: Viémont JD, Crabbé J (eds) Dormancy in plants: from whole plant behaviour to cellular control. CABI, Cambridge, p 385

Piotto B (1994) Effects of temperature on germination of stratified seeds of three ash species. Seed Sci Technol 22:519-529

SAS (1999) SAS/Star ${ }^{\mathbb{B}}$ users guide. Carey, NC, p 943

Suszka B (1978) Seed studies on bird cherry, beech, oak, ash and maple. In: Proceedings. Symposium on establishment and treatment of high quality hardwood forests in the temperate climatic region, Nancy-Chapenoux

Suszka B, Muller C, Bonnet-Massimbert M (1996) Seeds of forest broadleaves - from Harvest to Sowing. INRA Editions, Paris, $p$ 254

Tylkowski T (1990) Mediumless stratification and dry storage of afterripened seeds of Fraxinus excelsior L. Arbor Kornicke 35:143152

Villiers TA (1975) Dormancy and the survival of plants. Edward Arnold Limited, London, p 67

Villiers TA, Wareing PF (1965) The growth-substance content of dormant fruits of Fraxinus excelsior L. J Exp Bot 16:533-544

Wagner J (1996) Changes in dormancy levels of Fraxinus excelsior L. embryos at different stages of morphological and physiological maturity. Trees 10:177-182 